\title{
Adherence to Southern European Atlantic Diet and physical fitness on the atherogenic index of plasma in adolescents
}

\author{
Adesão à Dieta Atlântica do Sul da Europa e \\ aptidão física ao índice aterogênico do \\ plasma em adolescentes
}

\section{Adherencia a la Dieta Atlántica del Sur de Europa y condiciones físicas en el índice aterogénico de plasma en adolescentes}

César Agostinis-Sobrinho 1,2,3

Arieli Fernandes Dias 1

Caroline Brand 1

Sigute Norkiene 2

Sandra Abreu 3

Adroaldo Cezar Araujo Gaya

Anelise Reis Gaya 1

Luís Lopes 3

Carla Moreira 3

Jorge Mota 3

Rute Santos 3,4 doi: 10.1590/0102-311X00200418

\begin{abstract}
We sought (i) to evaluate the associations of cardiorespiratory fitness (CRF), muscular fitness $(M F)$ and Southern European Atlantic Diet (SEADiet) with atherogenic index of plasma (AIP) and (ii) to investigate de combined association of MF, CRF and SEADiet on AIP in adolescents. A cross-sectional schoolbased study was conducted on 493 adolescents (285 girls and 208 boys) aged 15-18 years, from the Portuguese Azorean Archipelago. CRF was measured by shuttle run test and MF by curl up and push up tests. Adherence to SEADiet was assessed with a semi-quantitative food frequency questionnaire (FFQ). The AIP was estimated as log (TG/HDL-C). Measures of pubertal stage and socioeconomic status were assessed. Linear regression showed a significant inverse association between MF (standardized $\beta=-0.165 ; p<0.001$ ), CRF (standardized $\beta=-0.081 ; p<0.030$ ) and SEADiet (standardized $\beta=-0.081$; $p<0.045)$ with AIP, after adjustments for age, sex, pubertal stage and parental education. Furthermore, participants classified with an optimal as well as those with' low adherence to a SEADiet but with LowMF/LowCRF had on average the highest $\operatorname{AIP}(F(7.482)=3.270 ; p=0.002)$. Moreover, optimal SEADiet with HighMF/HighCRF group showed the lowest AIP when compared with those with low adherence to a SEADiet with HighMF/HighCRF group $(p=0.03)$. AIP is inversely associated with MF, CRF and SEADiet. The low MF combined with a low CRF levels seems to overcome the potential healthy effect of having an optimal adherence to the SEADiet on AIP. However, an optimal adherence to SEADiet seems to improve the AIP in those adolescents with high fitness levels.
\end{abstract}

Diet; Cardiorespiratory Fitness; High-density Lipoproteins; Triglycerides; Adolescent

\author{
Correspondence \\ C. Agostinis-Sobrinho \\ Programa de Pós-graduação em Ciências do Movimento \\ Humano, Universidade Federal do Rio Grande do Sul. \\ Rua Felizardo 750, Porto Alegre, RS 90690-200, Brasil. \\ cesaragostinis@hotmail.com
1 Programa de Pós-graduação em Ciências do Movimento Humano, Universidade Federal do Rio Grande do Sul, Porto Alegre, Brasil.
2 Faculty of Health Sciences, Klaipeda University, Klaipeda, Lithuania.
3 Faculdade de Desporto, Universidade do Porto, Porto, Portugal. 4 School of Education, University of Wollongong, Wollongong, Australia.




\section{Introduction}

Although the clinical manifestations of cardiovascular disease (CVD) only occur in adulthood, the development of atherosclerosis asymptomatic phase begins early, often during childhood 1 . The atherogenic index of plasma (AIP) is a logarithmically transformed lipid profile ratio estimated using concentrations of triglycerides (TG) and high-density lipoprotein cholesterol (HDL-C), $\log$ (TG/HDL-C) 2 and it has been proven a better predictor of metabolic syndrome than other measures of lipid profile 3. Moreover, the AIP has been shown to positively associate with CVD risk 4.

Lifestyle changes can reduce the cardiometabolic risk, morbidity and mortality 5 . Lifestyle behaviors known to associate with CVD include, for example, poor dietary habits and physical inactivity 5. Physical fitness has been identified as an important determinant of cardiometabolic health in adolescence, as well as an indicator of future health status ${ }^{6}$. Cardiorespiratory fitness (CRF) and muscular fitness (MF) are associated with a favorable profile of adiposity, lipid, blood pressure and insulin sensitivity in childhood 7,8,9. In addition, CRF 10,11,12 and MF 13,14 are independently associated with an improved cardiometabolic health.

The Southern European Atlantic Diet (SEADiet) is characterized by the abundant consumption of little-processed, local, fresh and seasonal foods, including fruit, vegetables, bread, cereals and pulses, along with fish and milk by-products 15 . Although it has some similar elements with the Mediterranean diet such as consumption of vegetables and fruits, olive oil and nuts, the SEADiet has some differentiating characteristics such as the increased intake of fish and seafood, potatoes, broths with meat and cabbage, and moderate consumption of lean meats 16 . The adherence to this dietary pattern has been reported as being protective against CVD, indicating associations with reduced TG, insulin resistance, and systolic blood pressure 17 .

The cardiometabolic health in adolescence seems to track to adulthood 18. Besides, SEADiet 17, CRF 19,20 and MF 8 have been associated with metabolic health in childhood and adolescence. Moreover, limited research has examined some similar parameters and their potential additive associations with AIP in adults 21. Data from adolescents are missing. Thus, it's pertinent to try to understand the associations and combined effect of an adherence to a SEADiet and fitness components on AIP. Furthermore, to our knowledge, no studies have evaluated the combined association of these three variables on AIP in adolescents.

Therefore, this study sought (i) to evaluate the associations of CRF, MF and adherence to a SEADiet with AIP and (ii) to investigate de combined association of MF, CRF and SEADiet on AIP in adolescents.

\section{Methods}

\section{Study design, sampling procedures and participants}

Data for this investigation derived from a school-based study, the Azorean Physical Activity and Health Study II, which sought to evaluate physical activity, physical fitness, and prevalence of overweight/ obesity, dietary intake, health-related quality of life and related factors. Details on the study design and sampling strategy are reported elsewhere 22. This study was conducted in six of the nine Azorean Islands (São Miguel, Terceira, Faial, Pico, São Jorge and Graciosa), Portugal, in which 95\% of the Azorean population lives. The population was selected using proportionate stratified random sampling, considering the location (island) and number of students by age and sex in each school.

Data were collected for 1,525 adolescents, 36 excluded due to lack of information on several variables, and 297 for refusing to undergo blood sampling measurement. Therefore, the final sample included in this study was comprised of 493 adolescents that completed all interest variables ( 285 girls and 208 boys) aged 15-18 years (mean age 16.5). No differences between the variables of interest of the subjects who underwent and those who refused blood collection measurement were observed 22 . 


\section{Measures}

\section{- Southern European Atlantic Diet score}

Dietary intake of the previous 12 months was obtained using a self-administered, semi-quantitative food frequency questionnaire (FFQ), validated for Portuguese adults 23,24. The FFQ was adapted for adolescents by including foods more frequently eaten by this age 25 , comprising 91 food items or beverage categories 26 . Food intake was estimated by weight in one of the nine possibilities of frequency of consumption (from never or less than once per month, to six or more times a day), by the weight of the standard portion size of the food item. Energy and nutritional intake were estimated with the respondents' ratings of frequency, portion, and seasonality of each item, using the software Food Processor Plus (https://www.esha.com/). This program uses nutritional information from the United States that has been adapted with typical Portuguese foods and beverages. The Cronbach $\alpha$ test was applied to the dimensions of the FFQ to verify the inter-item consistency, and the score obtained $\alpha=0.892$.

The adherence to the traditional Southern European Diet was assessed by the SEAD index as reported by Oliveira et al. 15. The SEADiet score was originally constructed based on the intake of nine food groups, namely fresh fish (excluding cod), cod, red meat and pork products, dairy products, legumes and vegetables, vegetable soup, potatoes, whole-grain bread and wine. Each component (except wine) was measured as grams per 1,000kcal per day. Using the sex-specific median of the study's participants as a cut-off value for each of the components, 1 point was given when intake $\geq$ median and 0 points for intakes below median for all items except for wine ( $\leq 1$ glass/day in women and $\leq 2$ glasses/day in men $=1$ point). In this study, we adapted this score by attributing 0 points to any wine consumption since ethanol consumption is not recommended for children and adolescents. The participants that met all the characteristics of SEADiet had the highest score ( 9 points), reflecting maximum adherence. The participants that met none of the characteristics had minimum score (0), reflecting no adherence. Based on these results, participants were categorized into two groups: Low ( $\leq 4$ points) and High ( $\geq 5$ points) adherence according to the sample median.

\section{- Cardiorespiratory fitness}

CRF was assessed with the 20-meter shuttle run test as described elsewhere 27 . We estimated the maximum oxygen consumption (VO2 $\mathrm{max}, \mathrm{mL} / \mathrm{kg} / \mathrm{min}$ ) from the $20 \mathrm{~m}$ shuttle run test number of laps performed using the equation reported by Leger et al. 27. The participants were also classified into two CRF groups (Low and High), according to proposed cut-off for this population by Ruiz et al. 19.

\section{- Muscular fitness}

MF was evaluated using the curl-up and push-up tests. All tests were conducted according to the Fitnessgram measurement procedures 28 . The curl-up test was used to evaluate abdominal strength and endurance. Participants lie down with knees bent and feet unanchored. The adolescents complete as many repetitions as possible to a maximum of 75 set to a specified pace.

The push-up test was used to evaluate upper body strength and endurance. Participants lower the body to a 90-degree elbow angle and push up. The adolescents complete as many repetitions as possible set to a specified pace.

The results of the curl-up and push-up tests were transformed into standardized values (Z-scores) by age and sex for all sample. Then, the sum of the Z-scores of the two tests was performed to create the muscular fitness score 29. Participants were divided into two groups: Low MF (first tertile) and High MF (second and third tertiles) 13,29. 


\section{- Blood sampling}

Blood samples were obtained from each subject early in the morning, following a 10-hour overnight fast by vein puncture from the antecubital vein. The samples were stored in sterile blood collection tubes in refrigerated conditions $\left(4^{\circ}\right.$ to $8^{\circ} \mathrm{C}$ ) for no longer than 4 hours during the morning of collection and then sent to an analytical laboratory for testing according to standardized procedures, as follow: TG and HDL-C were determined by colorimetric methods using the Cobas Integra 400 Plus (Roche Diagnostics, Indianapolis, U.S.A.). The AIP was estimated as log (TG/HDL-C) ${ }^{4}$. All assays were performed in duplicate according to the manufacturers' instructions.

\section{- Anthropometrics}

Height was measured to the nearest millimeter in bare or stocking feet with the adolescent standing upright against a stadiometer (Holtain Ltd., Crymych, U.K.). Weight was measured to the nearest $0.10 \mathrm{~kg}$, with adolescents lightly dressed using a portable electronic weight scale (Tanita Inner Scan BC 532). All measurements were made according to the standardized manual 30.

\section{- Pubertal stage}

In both studies, participants self-assessed their pubertal stage of secondary sex characteristics (breast and pubic hair development for girls, genital and pubic hair development for boys; ranging from stage I to V), according to the criteria of Tanner \& Whitehouse 31.

\section{- Parental education}

The highest level of parental education (in completed years of education) was considered as a proxy of socioeconomic status. Similar procedures have also been applied in the Portuguese context 32.

\section{- Data management}

According to the adherence to a SEADiet (Optimal and Low), CRF group (High and Low) and MF (High and Low), eight exclusive groups were created: (1) low adherence to a SEADiet with LowMF/ LowCRF; (2) low adherence to a SEADiet with HighMF/LowCRF; (3) low adherence to a SEADiet with LowMF/HighCRF; (4) low adherence to a SEADiet with HighMF/HighCRF; (5) optimal adherence to a SEADiet with LowMF/LowCRF; (6) optimal adherence to a SEADiet with HighMF/LowCRF; (7) optimal adherence to a SEADiet with LowMF/HighCRF; (8) optimal adherence to a SEADiet with HighMF/HighCRF.

\section{Statistical analysis}

Descriptive data are presented as means and standard deviation. Independent two-tailed t-tests for continuous variables were used to examine sex differences. All models were evaluated for the normality of the residues, as well as the presence of residues higher than 3.3 standard deviations. The multicollinearity was also verified, using the variance inflation factor and correlation coefficient.

Linear regression models were performed to determine the associations between AIP with CRF, MF score and SEADiet, adjusted for age, sex, pubertal stage and parental education. The analysis was adjusted for total energy intake and low-energy reporter for the association between SEADiet and AIP. Standardized regression coefficients were used to express the $\beta$ coefficients of the regression analysis.

Analysis of covariance (ANCOVA) with Bonferroni post-hoc multiple comparison tests were used to assess the differences between mean values of AIP across the eight combined groups of SEADiet, MF and CRF. Covariates included were age, sex, pubertal stage total energy intake and lowenergy reporter.

Analysis was performed with the SPSS version 21.0 (https://www.ibm.com/). A p-value $<0.05$ denoted statistical significance. 


\section{Ethical approval}

All procedures performed in studies involving human participants were in accordance with the ethical standards of the institutional and/or national research committee and with the 1964 Helsinki Declaration and its later amendments or comparable ethical standards.

\section{Results}

Table 1 shows descriptive characteristics of the participants by sexes. Boys have higher levels of MF, CRF ( $\mathrm{p}<0.01$ for all), while girls presented lower values of HDL-C than boys $(\mathrm{p}<0.01)$.

The results of regression analyses are present in Table 2 , showing a significant inverse association between MF score (standardized $\beta=-0.165 ; \mathrm{p}<0.001$ ), CRF (standardized $\beta=-0.081 ; \mathrm{p}<0.030$ ) and adherence to a SEADiet (standardized $\beta=-0.081$; $\mathrm{p}<0.045$ ) with AIP, adjustments for age, sex, pubertal stage and parental education. The association between SEADiet and AIP was additionally adjusted for total energy intake, low-energy reporter.

Table 1

Participants' characteristics.

\begin{tabular}{|c|c|c|c|}
\hline Characteristics & $\begin{array}{c}\text { All }(N=493) \\
\text { Mean }(S D)\end{array}$ & $\begin{array}{c}\text { Girls }(n=285) \\
\text { Mean }(S D)\end{array}$ & $\begin{array}{c}\text { Boys }(n=208) \\
\text { Mean }(S D)\end{array}$ \\
\hline Age (year) & $16.50( \pm 0.90)$ & $16.51( \pm 0.91)$ & $16.50( \pm 0.86)$ \\
\hline Weight (kg) & $63.17( \pm 12.60)$ & $58.83( \pm 10.23)$ & $69.46( \pm 13.05)$ * \\
\hline Height $(\mathrm{cm})$ & $165.6( \pm 0.8)$ & $160.05( \pm 0.6)$ & $172.93( \pm 0.7)$ * \\
\hline Triglycerides (mg/dL) & $71.29( \pm 37.9)$ & $74.38( \pm 37.70)$ & $76.03( \pm 37.86)$ \\
\hline $\mathrm{HDL}-\mathrm{C}(\mathrm{mg} / \mathrm{dL})$ & $55.62( \pm 13.1)$ & $59.35( \pm 12.87)$ & $50.27( \pm 12.87)$ * \\
\hline AIP & $0.07( \pm 0.23)$ & $0.06( \pm 1.65)$ & $0.09( \pm 0.24)$ \\
\hline SEADiet score & $4.74( \pm 1.88)$ & $4.77( \pm 0.22)$ & $4.68( \pm 1.80)$ \\
\hline Total energy intake & $2,368.2( \pm 900)$ & $2,219.9( \pm 870)$ & $2,577.3( \pm 950)$ \\
\hline Curl-up (numer of curl-ups) & $35.71( \pm 22.52)$ & $30.45( \pm 21.2)$ & $43.45( \pm 21.2)$ * \\
\hline Push-up (number of push-ups) & $14.71( \pm 10.7)$ & $11.91( \pm 11.2)$ & $18.71( \pm 8.7)$ * \\
\hline MF score & $0.00( \pm 1.65)$ & $-0.48( \pm 1.65)$ & $0.69( \pm 1.39) *$ \\
\hline CRF & $38.34( \pm 7.5)$ & $33.9( \pm 4.5)$ & $44.31( \pm 6.5)$ \\
\hline
\end{tabular}

AIP: atherogenic index of plasma; CRF: cardiorespiratory fitness; HDL-C: high-density lipoprotein cholesterol;

MF: muscular fitness; SD: standard deviation; SEADiet: Southern European Atlantic Diet.

* Significantly different from girls, $p<0.01$ (independent two-tailed t-tests for continues variables).

Table 2

Standardized regression coefficients examining the association of cardiorespiratory fitness (CRF), muscular fitness (MF) and Southern European Atlantic Diet (SEADiet) with the atherogenic index of plams (AIP) adjusted for age, sex, pubertal stage and parental education.

\begin{tabular}{lccc}
\hline Dependent variable & \multicolumn{2}{c}{ AIP } & p-value \\
\hline MF score & $\mathbf{R}^{\mathbf{2}}$ & $\boldsymbol{\beta}$ & $<0.001$ \\
CRF & 0.025 & -0.165 & 0.030 \\
SEADiet * & 0.005 & -0.081 & 0.045 \\
\hline
\end{tabular}

* Additionally adjusted for underreports and total energy intake. 
Figure 1 shows the differences in the AIP across the eight exclusive created groups according to the SEADiet, CRF and MF status. Subjects classified as optimal adherence to a SEADiet HighMF/ HighCRF as well as those with low adherence to a SEADiet HighMF/HighCRF had on average the lowest AIP $(\mathrm{F}(7.482)=3.270 \mathrm{p}=0.002)$. Moreover, we found a significant difference between optimal SEADiet with HighMF/HighCRF group and low adherence to a SEADiet with HighMF/HighCRF group ( $\mathrm{p}=0.03$ ). No significant difference was found between optimal or low adherence to a SEADiet groups with LowMF/LowCRF.

\section{Discussion}

Our study showed important outcomes. Firstly, the AIP is inversely associated with MF, CRF and adherence to a SEADiet in adolescents. Secondly, the effects of a low MF, combined with a low CRF, seems to overcome the potential healthy effect of having an optimal adherence to the SEADiet on AIP. Thirdly, adolescents classified with a high adherence to a SEADiet along with HighMF/HighCRF showed the lowest AIP. These outcomes suggest the existence of an important inter-relationship (connection) among MF, CRF and adherence to a SEADiet on AIP. Although several studies have examined the association between MF 12,13,14, CRF 10 and adherence to a SEADiet 17 individually on metabolic health, none of them have evaluated the combination role of these three variables on AIP in healthy youths.

Our results partially agree with The Helena Study, which investigated the independent associations of MF and CRF with a clustered metabolic risk in 709 adolescents and showed that MF was negatively associated with clustered metabolic risk. An inverse association was also found between CRF and this risk factors 14. In addition, Steene-Johannessen et al. 12, showed an independently association of

\section{Figure 1}

Atherogenic index plasma across combined groups of adherence to Southern European Atlantic Diet - SEADiet (low adherence vs. optimal adherence), cardiorespiratory fitness - CRF (LowCRF/HighCRF) and muscular fitness - MF (LowMF/HighCRF).

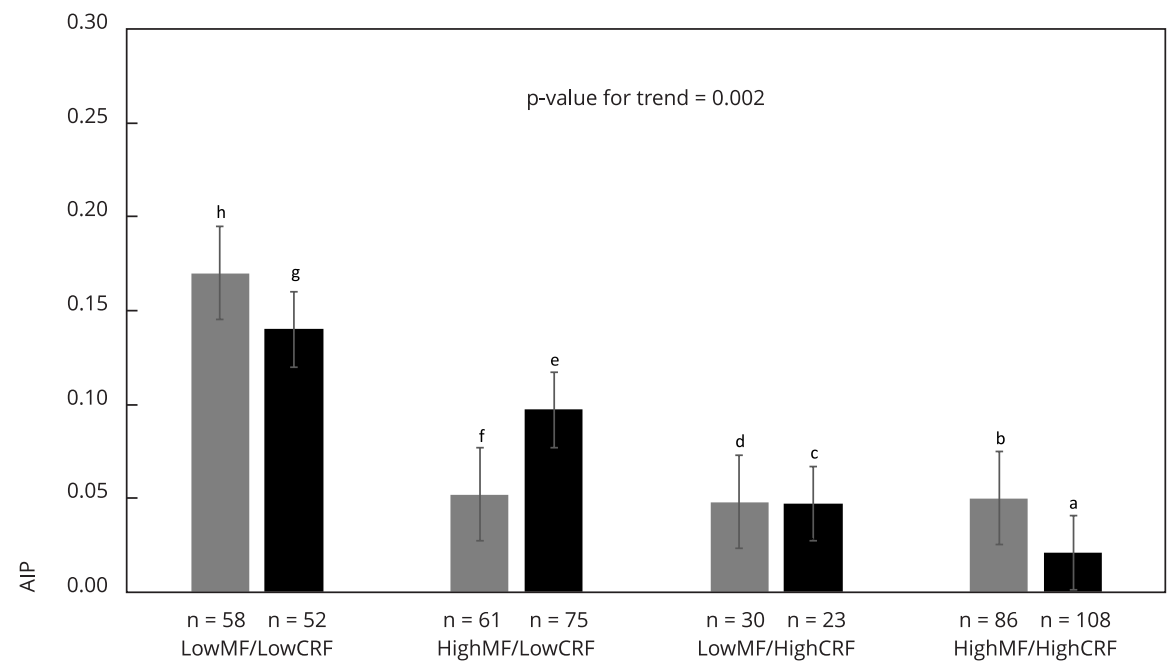

Low adherence to SEADiet
Optimal adherence to SEADiet

AIP: atherogenic index of plasma.

Note 1: bars represent adjusted means and $95 \%$ confidence intervals, for age, sex, pubertal stage, parental education and total energy intake and low-energy reporter as confounders.

Note 2: $a \neq(b-e-f-g-h) ; b \neq(e-h-g) ; c(a) ; d \neq(g-h) ; e(a-b-g) ; f \neq(g-h) ; g \neq(a-b-d-e-f) ; h \neq(a-b-d-f) ; p<0.05$ for all. 
MF and CRF on metabolic risk in Norwegian children and adolescents. In a cross-sectional study, with 1,234 children and adolescents from Southern Brazil, high levels of TG were more prevalent in those with low levels of cardiorespiratory fitness and obese 33. Likewise, the Avena Study adds new information, indicating that physical fitness is associated to lipid and metabolic cardiovascular risk in adolescents 34 . Higher CRF in boys and greater muscle strength in girls were associated with a better lipid profile 34 .

Our results also emphasize the key role of an optimal adherence to an Atlantic Diet. We showed that adolescents with high adherence to a SEADiet with HighMF/HighCRF have a lowest AIP when compared with those with low adherence to a SEADiet with HighMF/HighCRF. These results indicate that an optimal adherence to SEADiet seems to improve the cardiometabolic health effects in those adolescents with high fitness levels. The SEADiet have been associated to reduced TG, insulin resistance, and systolic blood pressure in youths ${ }^{19}$. Moreover, a recent study showed that an optimal rate of compliance with the SEADiet and physical activity is linked to lower cardiometabolic risk in adults 35 .

Date on the combined effects of diet quality and physical activity on CVD risk factors were investigated in 1,513 adolescents between 12.5 and 17.5 years old 36 . Results showed that being active was associated with higher CRF profile. Moreover, the results indicated that the healthy diet and active group had lower TG levels compared with the healthy diet but inactive group. Adolescents with an unhealthy diet but active had lower total cholesterol levels than their peers with a healthy diet but inactive 37 . Furthermore, adolescents with an unhealthy diet but active group had a lower TC/HDL-C ratio than those with an unhealthy diet and inactive. Collectively, these results agree with our report. Moreover, in our study we considered both, MF and CRF, showing a more complete picture of physical fitness and interaction of SEADiet on AIP.

Our results do support the current literature, which shows MF and CRF as important markers of cardiometabolic health in youth 8,9 and add new information showing the potential health effects of SEADiet and the importance of keeping healthy levels of MF and CRF, rather than just dietary care. This is very interesting considering that healthy behaviors do not always come together, as active adolescents may have, or not, a healthy diet and high levels of physical fitness 37,38 . Thus, even an adolescent with a healthy diet but inadequate levels of physical fitness may present cardiometabolic disorders. These results emphasize the relevance of physical fitness and support the current physical activity recommendations for youths, which include aerobic exercise and muscle strengthening activities 39 .

Finally, adolescents classified with LowMF/LowCRF had the highest AIP, which is worrying, considering that low levels of HDL-C and increased levels of TG may be present since childhood 40 . Developing actions and interventions to change this reality is essential, knowing that these variables are associated with lipid profile and overall metabolic health. Besides, physical fitness and diet are behavioral factors that can be encouraged and modified, especially in adolescence 41 .

Important strengths of this study include the evaluation of both independent and combined associations of three distinct variables with an under investigated marker of lipid profile that has been shown to associate with CVD. Moreover, our study emphasizes the potential utility of AIP (cheap and of easy access) as a predictor for cardiometabolic health. Such biomarker may have utility in motivating health professionals, public health workers, and adolescents' families toward lifestyle changes, improving early prevention efforts. In addition, our results have public health and clinical implications as adolescence has been reported as a period of life with several behavioral and metabolic changes. Future efforts are still necessary to identify pediatric clinical characteristics that could be used in screening tests to predict and prevent CVD risk in adulthood. Therefore, the increment of physical activity levels to improvement of muscle strength and aerobic fitness, and an adherence to a healthy diet may be an effective preventive strategy aimed at reducing and protecting against the atherosclerosis process.

Our impossibility to rule out some reporting bias is a limitation of our study since we used self-reported dietary intake data. However, this questionnaire was previously tested $42,43,44,45$ and the analyses were controlled to prevent the misreporting of energy intake. In addition, we used the validated questionnaire for Portuguese adults 23,24 added to the FFQ the foods more frequently eaten by adolescents 25 . This methodological approach to assess food intake was used in other studies with 
Portuguese adolescents using the same FFQ 42,43,44,45. Moreover, a study showed that adult FFQ can be used in adolescents from the same population 46. Finally, a cross-sectional study does not allow us to identify causal relationships.

In summary, our data suggest that AIP is inversely associated with MF, CRF and SEADiet. The low MF combined with a low CRF levels seems to overcome the potential healthy effect of having an optimal adherence to the SEADiet on AIP. However, an optimal adherence to SEADiet seems to improve the AIP in those adolescents with HighMF/HighCRF levels.

\section{Contributors}

C. Agostinis-Sobrinho and R. Santos were responsible for all aspects of the article, ensuring the accuracy and integrity of any part of the article. A. F. Dias and $\mathrm{C}$. Brand contributed to the study design and conception and data analysis and interpretation. C. Moreira, L. Lopes, and A. R. Gaya contributed to the article writing and relevant critical review of intellectual content. A. C. A. Gaya, S. Abreu, and J. Mota reviewed the final version of the paper. S. Norkiene participated in the study design, data interpretation, and review of the manuscript.

\section{Additional informations}

ORCID: César Agostinis-Sobrinho (0000-00019104-9042); Arieli Fernandes Dias (0000-00016648-8799); Caroline Brand (0000-0002-56243592); Sigute Norkiene (0000-0002-3231-5168); Sandra Abreu (0000-0002-6722-1575); Adroaldo Cezar Araujo Gaya (0000-0002-5941-5089); Anelise Reis Gaya (0000-0002-8335-6947); Luís Lopes (0000-0001-6680-0893); Carla Moreira (0000-0003-1039-6320); Jorge Mota (0000-00017571-9181); Rute Santos (0000-0002-7604-5753).

\section{Conflict of interests}

The authors have no conflicts of interest relevant to this article to disclose.

\section{Acknowledgments}

The author C.A.-S. was given Doctoral scholarship from the Brazilian Graduate Studies Coordinating Board (Capes; Proc: 9588-13-2). The Research Centre on Physical Activity Health and Leisure (CIAFEL) is supported by UID/DTP/00617/2013 (Science and Technology Foundation - FCT, Portuguese Ministry of Science). The authors C.B. and A.F.D. were given Doctoral scholarship from Capes. The author A.C.A.G. has a research fellowship from the Brazilian National Research Council (CNPq). J.M. was supported by grants: FCT: SFRH/ BSAB/142983/2018 and UID/DTP/00617/2019 as well as Programa de Bolsas Santander Universidades 2018. R.S. is supported by FCT (CEECIND/ 01069/2017). 


\section{References}

1. Balagopal PB, De Ferranti SD, Cook S, Daniels SR, Gidding SS, Hayman LL, et al. Nontraditional risk factors and biomarkers for cardiovascular disease: mechanistic, research, and clinical considerations for youth: a scientific statement from the American Heart Association. Circulation 2011; 123:2749-69.

2. Goff DC, Lloyd-Jones DM, Bennett G, Coady S, D’Agostino RB, Gibbons R, et al. ACC/AHA guideline on the assessment of cardiovascular risk: a report of the American College of Cardiology/American Heart Association Task Force on Practice Guidelines. Circulation 2013; 129:49-73.

3. Essiarab F, Taki H, Lebrazi H, Sabri M, Saile R. Usefulness of lipid ratios and atherogenic index of plasma in obese Moroccan women with or without metabolic syndrome. Ethn Dis 2014; 24:207-12.

4. Dobiásová L. AIP - atherogenic index of plasma as a significant predictor of cardiovascular risk: from research to practice. Vnitr Lek 2006; 52:64-71.

5. World Health Organization. Global recommendations on physical activity for health. Geneva: World Health Organization; 2010.

6. Ortega FB, Ruiz JR, Castillo MJ, Sjostrom M. Physical fitness in childhood and adolescence: a powerful marker of health. Int J Obes (London) 2008; 32:1-11.

7. Ruiz JR, Castro-Piñero J, Artero EG, Ortega FB, Sjöström M, Suni J, et al. Predictive validity of health-related fitness in youth: a systematic review. Br J Sports Med 2009; 43:909-23.

8. Smith JJ, Eather N, Morgan PJ, Plotnikoff RC, Faigenbaum AD, Lubans DR. The health benefits of muscular fitness for children and adolescents: a systematic review and meta-analysis. Sports Med 2015; 44:1209-23.

9. Ruiz JR, Huybrechts I, Cuenca-Garcia M, Artero EG, Labayen I. Meirhaeghe A, et al. Cardiorespiratory fitness and ideal cardiovascular health in European adolescents. Heart 2015; 101:766-73.

10. Agostinis-Sobrinho C, Moreira C, Mota J, Santos R. Proteína C-reativa, atividade física e aptidão cardiorrespiratória em adolescentes portugueses: um estudo transversal. Cad Saúde Pública 2015; 31:1907-15.

11. Bugge A, El-Naaman B, McMurray RG, Froberg K, Nielsen $\mathrm{CH}$, Müller K, et al. Inflammatory markers and clustered cardiovascular disease risk factors in Danish adolescents. Horm Res Paediatr 2012; 78:288-96.

12. Steene-Johannessen J, Kolle E, Andersen LB, Anderssen SA. Adiposity, aerobic fitness, muscle fitness, and markers of inflammation in children. Med Science Sport Exerc 2013; 45:714-21.

13. Agostinis-Sobrinho C, Moreira C, Abreu S, Lopes L, Sardinha LB, Oliveira-Santos J, et al. Muscular fitness and metabolic and inflammatory biomarkers in adolescents: results from LabMed Physical Activity Study. Scand J Med Sci Sports 2016; 27:1873-80.
14. Artero EG, España-Romero V, Jiménez-Pavón D, Martinez-Gómez D, Warnberg J, GómezMartínez S, et al. Muscular fitness, fatness and inflammatory biomarkers in adolescents. Pediatr Obes 2013; 9:391-400.

15. Oliveira A, Lopes C, Rodriguez-Artalejo F. Adherence to the Southern European Atlantic Diet and occurrence of nonfatal acute myocardial infarction. Am J Clin Nutr 2010; 92:211-7.

16. Vaz-Velho M, Pinheiro R, Rodriguez S. The Atlantic Diet: origin and features. International Journal of Food Studies 2016; 5:106-19.

17. Guallar-Castillón P, Oliveira A, Lopes C, López-García E, Rodríguez-Artalejo F. The Southern European Atlantic Diet is associated with lower concentrations of markers of coronary risk. Atherosclerosis 2013; 226:502-9.

18. Harding S, Silva MJ, Molaodi OR, Enayat ZE, Cassidy A, Karamanos A, et al. Longitudinal study of cardiometabolic risk from early adolescence to early adulthood in an ethnically diverse cohort. BMJ Open 2016; 6:e013221.

19. Ruiz JR, Cavero-Redondo I, Ortega FB, Welk GJ, Andersen LB, Martinez-Vizcaino V. Cardiorespiratory fitness cut points to avoid cardiovascular disease risk in children and adolescents; what level of fitness should raise a red flag? A systematic review and meta-analysis. Br J Sports Med 2016; 50:1451-8.

20. Agostunis-Sobrinho C, Ruiz JR, Moreira C, Abreu S, Luís L, Oliveira-Santos J, et al. Cardiorespiratory fitness and inflammatory profile on cardiometabolic risk in adolescents from the LabMed Physical Activity Study. Eur J Appl Physiol 2017; 117:2271-9.

21. Edwards MK, Blaha MJ, Loprinzi PD. Influence of sedentary behavior, physical activity, and cardiorespiratory fitness on the atherogenic index of plasma. J Clin Lipidol 2017; 11:119-25.

22. Moreira C, Santos R, Vale S, Soares-Miranda L, Marques AI, Santos PC, et al. Metabolic syndrome and physical fitness in a sample of Azorean adolescents. Metab Syndr Relat Disord 2010; 8:443-9.

23. Lopes C, Aro A, Azevedo A, Ramos E, Barros $H$. Intake and adipose tissue composition of fatty acids and risk of myocardial infarction in a male Portuguese community sample. J Am Diet Assoc 2007; 107:276-86.

24. Lopes CM. Alimentação e enfarte agudo do miocárdio: um estudo caso-controlo de base populacional [PhD Thesis]. Porto: Universidade do Porto; 2000.

25. Silva D, Rego C, Guerra A, Sinde S, Zara L, Moreira P. Characterization of food habits and comparative study between two methods of food assessment in adolescents. Rev Aliment Hum 2004; 10:33-40.

26. Ramos E. Health determinants in Porto adolescents: the Epiteen cohort [PhD Thesis]. Porto: Universidade do Porto; 2006. 
27. Leger LA, Mercier D, Gadoury C, Lambert J. The multistage 20 metre shuttle run test for aerobic fitness. J Sports Sci 1998; 6:93-101.

28. Welk GJ, Meredith MD, editors. Fitnessgram/ Activitygram reference guide. Dallas: Cooper Institute; 2008.

29. Agostinis-Sobrinho C, Abreu S, Moreira C, Lopes L, García-Hermoso A, Ramírez-Vélez R, et al. Muscular fitness, adherence to the Southern European Atlantic Diet and cardiometabolic risk factors in adolescents. Nutr Metab Cardiovasc Dis 2017; 27:695-702.

30. Lohman TG, Roche AF, Martorell F, Martorell R. Anthropometric standardization reference manual. Champaign: Human Kinetics Books; 1991.

31. Tanner JM, Whitehouse RH. Clinical longitudinal standards for height, weight, height velocity, weight velocity, and stages of puberty. Arch Dis Child 1976; 51:170-99.

32. Mota J, Silva G. Adolescent's physical activity: association with socio-economic status and parental participation among a Portuguese sample. Sport Educ Soc 1999; 4:193-9.

33. Reuter CP, Silva PT, Renner JDP, Mello ED, Valim ARM, Pasa L, et al. Dyslipidemia is associated with unfit and overweight-obese children and adolescents. Arq Bras Cardiol 2016; 106:188-93.

34. Garcia-Artero E, Ortega FB, Ruiz JR, Mesa JL, Delgado M, González-Gross M, et al. Lipid and metabolic profiles in adolescents are affected more by physical fitness than physical activity (AVENA study). Rev Esp Cardiol 2007; 60:581-8.

35. Rodríguez-Martín C, Garcia-Ortiz L, Rodriguez-Sanchez E, Maderuelo-Fernandez C, Lugones-Sanchez A, Martin-Cantera MS, et al. The relationship of the Atlantic Diet with cardiovascular risk factors and markers of arterial stiffness in adults without cardiovascular disease. Nutrients 2019; 11:E742.

36. Cuenca-García M, Ortega FB, Ruiz JR, González-Gross M, Labayen I, Jago R, et al. Combined influence of healthy diet and active lifestyle on cardiovascular disease risk factors in adolescents. Scand J Med Sci Sports 2014; 24:553-62.
37. Jago R, Ness AR, Emmett P, Mattocks C, Jones L, Riddoch CJ. Obesogenic diet and physical activity: independent or associated behaviours in adolescents? Public Health Nutr 2010; 13:673-81.

38. Ottevaere C, Huybrechts I, Benser J, De Bourdeaudhuij I, Cuenca-Garcia M, Dallongeville $\mathrm{J}$, et al. Clustering patterns of physical activity, sedentary and dietary behavior among European adolescents: the HELENA study. BMC Public Health 2011; 11:328.

39. U.S. Department of Health and Human Services. Physical activity guidelines for Americans. Washington DC: U.S. Department of Health and Human Services; 2008.

40. Lartey A, Marquis GS, Aryeetey R, Nti H. Lipid profile and dyslipidemia among school-age children in urban Ghana. BMC Public Health 2018; 18:320.

41. Muros JJ, Cofre-Bolados C, Arriscado D, Zurita F, Knox E. Mediterranean diet adherence is associated with lifestyle, physical fitness, and mental wellness among 10-y-olds in Chile. Nutrition 2017; 35:87-92.

42. Araújo J, Severo M, Lopes C, Ramos E. Food sources of nutrients among 13-year-old Portuguese adolescents. Public Health Nutr 2011; 14:1970-8.

43. Bessa M, Valente H, Cordeiro T, Padrao P, Moreira A, Lopes C, et al. Fluid intake and overweight risk in children. Acta Med Port 2008; 21:161-70.

44. Cruz F, Ramos E, Lopes C. Tracking of food and nutrient intake from adolescence into early adulthood. Nutrition 2018; 55:84-90.

45. Fraga S, Severo M, Costa D, Lopes C, Ramos E. Clustering behaviours among 13-year-old Portuguese adolescents. J Public Health 2011; 19 Suppl 1:S21-7.

46. Shatenstein B, Amre D, Jabbour M, Feguery $\mathrm{H}$. Examining the relative validity of an adult food 430 frequency questionnaire in children and adolescents. J Pediatr Gastroenterol Nutr 2010; 51:645-52. 


\section{Resumo}

O estudo teve como objetivos: (i) avaliar as associações entre a aptidão cardiorrespiratória (ACR), aptidão muscular (AM) e Dieta Atlântica do Sul da Europa (SEADiet) e o índice aterogênico do plasma (IAP) e (ii) investigar a associação combinada entre AM, ACR e SEADiet e IAP em adolescentes. Foi realizado um estudo transversal de base escolar em uma amostra de 493 adolescentes (285 do sexo feminino), entre 15 e 18 anos de idade, nos Arquipélago dos Açores, Portugal. A ACR foi medida pelo teste aeróbico de corrida de vai-evem e a AM pelos testes de abdominal modificado e de flexão. A adesão ao SEADiet foi avaliada através de um questionário semi-quantitativo de frequência alimentar. O IAP foi calculado como $\log (T G / H D L-C)$. Foram avaliadas as medidas de estágio de puberdade e de nível socioeconômico. A regressão linear revelou uma associação inversa significativa entre AM ( $\beta$ padronizado $=$ -0,165; $p<0,001), A C R$ ( $\beta$ padronizado = -0,081; $p<0,030)$ e SEADiet ( $\beta$ padronizado $=-0,081$; $p<0,045)$ e IAP, depois de ajustar para idade, sexo, estágio de puberdade e escolaridade dos pais. Além disso, os participantes classificados como adesão excelente ou baixa ao padrão alimentar SEADiet mas com BaixaAM/BaixaACR, tiveram, em média, os maiores níveis de IAP $(F(7,482)=3,270$; $p=0,002)$. O grupo com adesão excelente ao SEADiet e AltaAM/AltaACR mostrou IAP mais baixo, comparado com o grupo com baixa adesão ao padrão alimentar SEADiet e AltaAM/AltaACR $(p=0,03)$. O IAP está associado inversamente com AM, ACR e SEADiet. Os níveis baixos de AMe $A C R$ parecem contrabalançar o efeito saudável potencial da adesão excelente ao padrão alimentar SEADiet sobre o IAP. Entretanto, a adesão excelente ao SEADiet parece melhorar o IAP nos adolescentes com níveis altos de aptidão física.

Dieta; Aptidão Cardiorrespiratória; Lipoproteínas de Alta Densidade; Triglicerídeos; Adolescente

\section{Resumen}

Nuestro objetivo (i) fue evaluar las asociaciones de las condiciones cardiorrespiratorias (CRF), musculares (MF) y de la Dieta Atlántica del Sur de Europa (SEADiet), con el indice aterogénico de plasma (AIP), así como (ii) investigar la asociación combinada de MF, CRF y SEADiet en el AIP en adolescentes. Se trata de un estudio transversal, basado escolares, que se dirigió a 493 adolescentes (285 niñas), con edades comprendidas entre los 15 a 18 años, procedentes del archipiélago portugués de las Azores. Las CRF se midieron mediante una prueba de sprint $y$ las MF mediante pruebas con flexiones y abdominales. La adherencia a la SEADiet se evaluó con un cuestionario semicuantitativo sobre la frecuencia de las comidas. El AIP se calculó como log (TG/HDL-C). Se evaluaron las medidas de la fase puberal y el estatus socioeconómico. La regresión lineal mostró una asociación significativa inversa entre MF ( $\beta$ estandarizado $=$ $-0,165 ; p<0,001), C R F$ ( $\beta$ estandarizado $=-0,081$; $p<0,030)$ y SEADiet $(\beta$ estandarizado $=-0,081$; $p<0,045)$ con el AIP, tras los ajustes por edad, sexo, fase puberal y educación parental. Asimismo, los participantes clasificados con una adherencia muy buena, asi como los que tuvieron una baja adherencia a la SEADiet, pero con BajasMF/ BajasCRF contaron con el promedio más alto en el $A I P(F(7.482)=3.270 ; p=0,002)$. Además, el grupo con una muy buena SEADiet con AltasMF/ AltasCRF mostró el más bajo AIP, cuando se compara con el grupo que tenía una baja adherencia a la SEADiet con AltasMF/AltasCRF ( $p=0.03)$. El AIP está inversamente asociado con MF, CRF y SEADiet. La baja MF, combinada con los niveles bajos de CRF, parece superar el efecto potencial saludable de contar con una muy buena adherencia a la SEADiet en el AIP. No obstante, una muy buena adherencia a la SEADiet parece mejorar el AIP en aquellos adolescentes con altos niveles de condición física.

Dieta; Capacidad Cardiovascular; Lipoproteinas de Alta Densidad; Triglicéridos; Adolescente
Submitted on $18 /$ Oct $/ 2018$

Final version resubmitted on 23/May/2019

Approved on 03/Jun/2019 